\title{
PANORAMA SOCIOPOLÍTICO EN COSTA RICA (2018): UNA LECTURA CIUDADANA
}

\section{SOCIO-POLITICAL PANORAMA IN COSTA RICA (2018): A CITIZEN READING}

\author{
Bernal Herrera Montero \\ bernalhe@yahoo.com \\ Universidad de Costa Rica
}

Recibido: 15 de junio de 2018 • Aceptado: 30 de junio de 2018 • Publicado: 9 de octubre de 2018

\begin{abstract}
Resumen
El ensayo ofrece una lectura del proceso electoral costarricense del 2018, de su inserción en la historia nacional de las últimas décadas y de algunos de los principales reacomodos sociopolíticos generados por dicho proceso. Se exploran ciertos factores que lo definieron: la dinámica político-partidaria tras la crisis del bipartidismo, el crecimiento de la inequidad socioeconómica, así como los diferenciados efectos de la incompleta modernización social y económica de las últimas décadas. Se proponen explicaciones parciales del enfrentamiento surgido entre una visión cristiano-conservadora y otra laica-modernizante, así como de su posterior evolución. Se propone que tal enfrentamiento, lejos de girar alrededor de temas "menores", permitió repensar algunos de los fundamentos últimos de la coexistencia social nacional.
\end{abstract}

Palabras clave: modernización, partidos costarricenses, desigualdad, derechos humanos, religión y política. 


\begin{abstract}
The essay offers a reading of the Costa Rican electoral process of 2018, of its insertion in the national history of the last decades, and of some of the main socio-political rearrangements generated by this process. Some of the factors that defined it are explored: political-party dynamics after the crisis of bipartisanship, the growth of socioeconomic inequality, and the differentiated effects of the incomplete social and economic modernization of the last decades. Partial explanations of the confrontation emerged between a Christian-conservative and a secular-modernizing vision, as well as its subsequent evolution. It is proposed that such confrontation, far from revolving around "minor" issues, allowed us to rethink some of the ultimate foundations of national social coexistence.
\end{abstract}

Keywords: modernization, Costa Rican parties, inequality, human rights, religion and politics.

La lectura del actual panorama sociopolítico nacional aquí propuesta sistematiza y contextualiza lo que numerosas personas sin duda ya han pensado y dicho. No es ni pretende ser un análisis técnico o académico, sino una versión del proceso, por un académico de las humanidades interesado en temas políticos e históricos. Parafraseando a Borges, no me interesa la originalidad, sino la posible verdad de la versión presentada, que, sin ser neutral, rehuye el carácter emotivo cuando no bilioso tan frecuente hoy día en muchos discursos que circulan sobre, entre otros temas, la política y sus actores.

Es posible que, en el largo plazo, el actual panorama sociopolítico costarricense acabe mostrando más continuidades que rupturas salvo, tal vez, en el nivel político-partidario. Pero visto hoy, con visión de corto plazo, su carácter más llamativo son las crisis y las rupturas, al ser el elemento de mayor calado la polarización evidenciada y promovida por el proceso electoral. Tras imperar por décadas, la imagen de una Costa Rica unida, solidaria y relativamente homogénea empezó a hundirse, al aflorar y agudizarse tanto diferencias como conflictos preexistentes, antes minimizados o invisibilizados.

No es casual que la plena entrada del país a las llamadas "guerras culturales" ("culture wars") contemporáneas la desencadenara la opinión consultiva de un organismo internacional: la Corte Interamericana de Derechos Humanos (CIDH). Tras el enfrentamiento armado del 48, el cual culmina una polarización que remonta al menos a la gran huelga bananera de 1932 y se agudiza en la década de los 40, la sociedad costarricense optó 
por ignorar, silenciar o minimizar sus conflictos sociales (ver Solís, 2011). Estos conflictos, comparados con los de otros países del área, han sido relativamente menores, pero han marcado la historia de Costa Rica como nación independiente, al día de hoy.

\section{Modernidad desigual, conflictividad sociocultural y crisis de la imagen nacional}

La violencia del 48, en la que desembocaron diversos conflictos y violencias previas, produjo un resultado inesperado, pues no solo conservó las principales conquistas sociales del bando derrotado, sino que originó procesos de orientación socialdemócrata, que atenuaron la conflictividad social, mejoraron las condiciones de vida de los sectores populares, fortalecieron y ampliaron las clases medias, así como renovaron las élites, todo ello enmarcado en una modernización del país. Los resultados del proyecto socialdemócrata fueron significativos; son un buen ejemplo los cambios en los patrones de mortalidad y natalidad: la mejoría de las condiciones sanitarias y la extensión de los servicios de salud bajaron la mortalidad infantil e incrementaron el promedio de vida, mientras las políticas de control de la natalidad, enmarcadas en la modernización cultural y la creciente urbanización de la población, llevaron a una drástica reducción en los índices de fecundidad.

Pero los procesos de modernización y mejora de las condiciones de vida fueron muy desiguales. Ninguno de ellos alcanzó los mismos resultados en las zonas rurales, en especial las más alejadas del área metropolitana, lo que mantuvo o incluso acentuó la dicotomía entre la Costa Rica urbana y la rural. Partes de la rural serían absorbidas por la urbanización y otras mantuvieron su condición de periferia nacional. Además, el apoyo de la Iglesia católica a las reformas de Calderón Guardia se había dado a cambio de la autorización para crear, especialmente en las zonas urbanas, numerosas instituciones privadas de educación primaria y secundaria a cargo de órdenes religiosas (cf. Molina, 2016, pp. 330-331). Así, mientras en las áreas rurales el menor impacto de la mejora de condiciones de vida y de los procesos modernizadores produjo un rezago grosso modo proporcional a su distancia del área metropolitana, en esta última la Iglesia empezó a controlar la educación 
de buena parte de las clases medias y las élites, lo que reforzó su considerable cuota de poder cultural y debilitó el proceso de laicización educativa iniciado por los liberales en el siglo XIX. A partir de los años 40, el país sin duda se modernizó, pero mantuvo desigualdades geográficas y culturales notables. Las regiones rurales quedaron rezagadas frente a las urbanas, y en estas la Iglesia impuso una moral tradicionalista en la mayoría de los temas asociados con la sexualidad y los derechos reproductivos, todo lo cual saltó con fuerza durante el reciente proceso electoral.

Muchas de las principales desigualdades nacionales se evidencian en su geografía humana, algunas de cuyas facetas, como la bajísima densidad de población en la cordillera de Talamanca, han sido muy influidas por la geografía física. Otras, en cambio, como la aguda concentración de la población en la Gran Área Metropolitana (GAM) y el escaso poblamiento de las zonas costeras, obedecen más a factores históricos y culturales. A partir de la incipiente colonización española del siglo XVI, la mayoría de la población y la actividad económica radicaron en los valles centrales intermontanos, distribución que continuó cuando el país profundizó su inserción en la economía internacional, primero con la exportación de café, a la que luego se añadió la de banano para, posteriormente, diversificarse. El énfasis en las exportaciones obligó a contar con infraestructura portuaria para el creciente tránsito de mercancías y, en menor medida, de personas, pero ello se logró sin necesidad de desarrollar y poblar las zonas costeras. Surge así un país que, pese a tener acceso directo a los dos principales océanos del mundo, una economía orientada a la exportación y puertos que definieron las principales rutas de ferrocarril, emblema de la modernidad a fines del XIX y principios del XX, mantuvo el rezago de sus zonas costeras (cf. Putnam, 2013; Viales Hurtado. 2013; Viales Hurtado, 1998).

A esta división de su geografía humana se unen grandes diferencias económicas, sociales y culturales. Costa Rica es una sociedad muy heterogénea, pero esto fue históricamente minimizado, cuando no negado o invisibilizado, en las principales imágenes que el país produjo sobre sí mismo, que delineaban una Costa Rica de población mayoritariamente blanca, gran igualdad social y un clima de paz y armonía a veces visto como inherente al carácter nacional (cf. Jiménez Matarrita, 2002). Como puede ocurrir con los estereotipos, estos contienen alguna dosis de verdad. En la Costa Rica 
del XIX, numerosos gobiernos fueron derrocados por golpes de Estado, pero no hubo las guerras civiles ni los caudillos que asolaron a otros países latinoamericanos en ese período. Y si bien en el siglo XX hubo golpe de estado, fraudes electorales (cf. Molina y Lehoucq, 1999) y una violencia que culminó en los enfrentamientos del 48, también estas convulsiones fueron mucho menores que las de otros países del área y fuera de esta (cf. Pérez Brignoli, 2018, pp. 540-544). Lo mismo puede decirse de las desigualdades sociales, desde el XIX hasta hoy día. Tenemos entonces un país menos desigual y violento que muchos otros, pero bastante más desigual y violento que lo que la imagen dominante reconoce y transmite. Costa Rica no es hoy, ni lo fue en el pasado, el país homogéneo que aparece en las imágenes y discursos oficiales. Lejos de reducirse, algunas desigualdades se acentuaron las últimas décadas, y, en el presente, existen y persisten poblaciones que sufren distintas formas y grados de marginalización, exclusión y discriminación: indígenas, afrocostarricenses, población LGBT, madres solteras pobres, en especial las adolescentes, y un largo etcétera (cf. los distintos informes del programa Estado de la Nación).

Las desigualdades en condiciones de vida, acceso a servicios, respeto de derechos y, en general, oportunidades para una vida digna y emprender proyectos de vida alternativos, emergieron a la superficie en las elecciones del 2018. Los conflictos se expresaron no a propósito de temáticas estrictamente socioeconómicas, aunque sí claramente impactados por estas, sino de divisiones socioculturales. El principal conflicto, en especial hasta la primera vuelta, enfrentó a los sectores de la población que apoyaban, en diversos grados, la modernización sociocultural del país, en concreto el matrimonio civil igualitario y un Estado laico, y los sectores, mayoritaria pero no exclusivamente populares, que abogaban por mantener e incluso restaurar una sociedad regida por creencias religiosas de corte tradicional. Aunque el país parecía tener problemas más acuciantes como la creciente inequidad, el déficit y la reforma fiscales, sumados a las políticas económicas y sociales, estos pasaron a un segundo plano.

El detonante es conocido: la opinión consultiva OC-24-17 emitida por la CIDH (accesible en www.corteidh.or.cr/docs/opiniones/seriea_24_esp. pdf), cuyo carácter vinculante ha sido ratificado por la Sala Constitucional, sobre la necesidad de que el país reconozca y garantice derechos hasta ahora 
negados a las minorías sexuales. Pero el enfrentamiento venía de antes, en temas como el estado laico y la fertilización in vitro, sobre la cual la misma CIDH ya se había pronunciado, haciendo ver que el país estaba negando derechos importantes, en este caso, a matrimonios y parejas heterosexuales. En un país acostumbrado a evitar el conflicto surgieron agrias discusiones y polémicas. Los pronunciamientos de la CIDH constituyeron, además, un cuestionamiento implícito pero contundente a uno de los pilares de la imagen nacional: la de Costa Rica como un país líder en derechos humanos. Para esta, una nación pequeña, sin ejército, de escaso peso económico y casi nulo peso geopolítico, los derechos humanos, como la protección al ambiente, han sido un ámbito en el que se reclama una autoridad moral que le permite enorgullecerse e incluso dar lecciones a países poderosos. El David de los derechos humanos, capaz de defenderlos ante los Goliats mundiales, no solo era acusado de irrespetar diversos derechos, sino incapaz, en el caso de la fecundación in vitro, de ponerse en regla aun después de una sentencia explícita y de medidas cautelares dictadas por la CIDH, un organismo nacido en Costa Rica, impulsado por este país, y asentado aquí, al menos en parte, por el prestigio nacional en el tema de derechos humanos.

Se trataba, entonces, de un cuestionamiento a fondo, hecho con criterios jurídicos por una institución respetada, sobre un tema crucial para el país. Visto así, resulta menos sorprendente que la campaña electoral, iniciada con tópicos socioeconómicos como la creación de empleo, haya pasado rápidamente a focalizarse en temas socioculturales. Primero los derechos de la población homosexual, luego el asunto general de los derechos humanos y de ahí al meollo de la cuestión: las distancias entre la imagen y la realidad del país, el modelo de sociedad vigente y aquel al que se aspiraba, los fundamentos jurídicos y culturales que debían cimentar la vida social. Se había pasado, en resumen, de discutir temas muy concretos a debatir los fundamentos mismos de la convivencia social.

Al principio la discusión giró, o pareció girar, alrededor de una disyuntiva clara: ¿debería el país profundizar su modernización y ampliar los derechos humanos que reconoce, o defender los valores religiosos de la mayoría? A diferencia del bando conservador, el modernizante articuló una visión de futuro, pero ambos apelaron por igual a la tradición. La imagen del país recalcaba temas como los derechos humanos y la protección del ambiente, 
asociados a una modernidad laica y hasta científica, pero no menos fuerte, aunque sí menos cacareada era la impronta de la cultura religiosa, no solo en los ámbitos rurales alejados de la modernización urbana, sino también en las ciudades, gracias al carácter religioso, en especial católico, del grueso de mucha de la educación privada primaria y secundaria. Diversas facetas del país se habían modernizado, pero otras seguían regidas por una moralidad religiosa y tradicionalista. Era esta contradicción, con la que el país había vivido largo tiempo, la que las acciones de la CIDH había sacado a la superficie, forzando a discutirla.

Pero si ella había saltado a propósito de temas socioculturales, expresaba también otros tipos de divisiones y contradicciones. Las más importantes eran de índole socioeconómica y tenían encarnaciones geográficas. También operaban procesos políticos partidarios. Así, se pusieron en juego más temas y factores que los que dominaron la campaña, en especial hasta la primera vuelta. La discusión, emprendida y seguida por muy diversos grupos desde sus respectivas concepciones y filiaciones socioculturales, tuvo manifestaciones políticas y consecuencias electorales que cambiarían significativamente conforme avanzaba el proceso electoral.

\section{Primer clivaje sociopolítico}

En una primera etapa, el conflicto sociocultural enfrentó, como no sucedía desde las reformas liberales del XIX, dos concepciones antagónicas sobre cuáles debían ser los valores éticos y fundamentos jurídicos de la sociedad costarricense. Para la visión conservadora cristiana los valores debían ser los de la religión cristiana, que las leyes no deberían contradecir. Por normas cristianas no se entendían las dadas por Cristo en los evangelios, sino las muy diferentes de la Iglesia católica y las evangélicas. Ello implicaba, por ejemplo, la defensa de la así llamada "familia natural"; el rechazo de formas de fecundación como la in vitro, y, en general, un rechazo a los derechos sexuales, reproductivos e identitarios de nueva generación. Para sus defensores, las decisiones de la CIDH constituían una nefasta arremetida contra valores básicos de una cultura nacional definida como cristiana, arremetida que debía ser rechazada incluso mediante la salida del país de la CIDH. En suma, un rechazo frontal a adecuar la legislación nacional a los 
modernos estándares internacionales en derechos humanos, y la negación de cualquier legitimidad legal o social a diversos cambios ya ocurridos en la cultura del país. La otra visión, laica y modernizante, sostenía que los principios jurídicos y las normas de convivencia cotidiana debían ser laicos, sin interferencias religiosas, definidos a la luz de las modernas teorías y prácticas sobre los derechos humanos, y, a modo global, la necesidad de profundizar la modernización de la sociedad costarricense.

Se discutieron con fuerza temas como la conveniencia del estado laico, el respeto a los derechos de las minorías sexuales y la necesidad de que las creencias cristianas dejaran de regir la aprobación de las leyes civiles, encarando a quienes veían a Costa Rica como un país cristiano enfrentado a la pérdida de valores y las acciones de organismos externos; a quienes lo veían como un país cuya modernización, incompleta y amenazada por el bando cristiano-conservador, debía profundizarse.

El conflicto entre estas dos visiones mandó temas como el empleo y la corrupción, prominentes al inicio del proceso electoral, a un segundo plano. Los candidatos que habían encabezado las encuestas, Antonio Álvarez Desanti (PLN) y Juan Diego Castro (PIN), empezaron a perder terreno, mientras los que mejor representaban las visiones en pugna, Carlos Alvarado (PAC) y Fabricio Alvarado (RN), hasta ese momento con una presencia muy débil en las encuestas, empezaron a crecer con rapidez. El crecimiento de Carlos Alvarado, aunque improbable no era del todo inesperado. Era el candidato de un partido consolidado, quien tras varias campañas ya era una opción viable frente al bipartidismo tradicional que había perdido las anteriores elecciones. El crecimiento de Fabricio Alvarado, en cambio, candidato de un partido cuyo único diputado era el propio Fabricio, fue mucho más sorpresiva. Pero el conflicto sociocultural que lo impulsó venía produciendo desde antes el crecimiento paulatino de las diputaciones de los partidos evangélicos y de los que, sin serlo, se aliaban con ellos en la Asamblea Legislativa, alianzas que culminaron con la elección de uno de sus diputados como presidente de la Asamblea en el 2017.

La primera vuelta electoral acabó, entonces, transformada en una especie de referendo sobre el camino que el país debería seguir en temas concretos como los derechos reproductivos y de las minorías sexuales, y, en general, sobre el rol de la religión y de la modernidad en la sociedad costarricense. 
Pero también evidenció otras diferencias y conflictos sociales, económicos y políticos, así como una relación consistente entre la condición socioeconómica y las preferencias electorales. Los cantones con menores índices de desarrollo humano apoyaron la visión cristiano-conservadora y los de mayor desarrollo humano, la visión laico-progresista. Los grupos poblacionales con menores recursos económicos, nivel de escolaridad y acceso a servicios básicos apoyaron la visión cristiano-conservadora y los sectores con más recursos económicos, nivel de escolaridad y acceso a servicios, la visión laico-modernizante. Ello implicó una clara división geográfico-electoral: las áreas costeras y fronterizas apoyaron la visión cristiano-conservadora; las áreas urbanas de la Gran Área Metropolitana, la visión laico-modernizante. Es claro que no todas las personas en condiciones de rezago socioeconómico y educativo votaran por Fabricio, ni que todas las personas de clase media y alta votaran por Carlos. Por citar un ejemplo, es muy probable que los sectores más conservadores del catolicismo, como el Opus Dei, apoyaran a Fabricio, pese a ser urbanos y tener altos ingresos y niveles de escolaridad.

Si los temas explícitos que definieron la primera vuelta fueron de tipo sociocultural, la demografía de sus resultados evidenció que detrás de ellos actuaban otras temáticas y realidades, al igual que la polarización no expresaba solo la dicotomía entre las dos visiones en pugna, sino también distancias y rezagos socioeconómicos con fuerte anclaje geográfico. Se evidenció, en suma, la existencia de poblaciones separadas por la muy desigual distribución del ingreso y el algo menos desigual acceso a servicios como educación y salud. La visión de Costa Rica como un país sin las agudas diferencias sociales de otras sociedades quedó seriamente dañada. La sorpresa era relativa, pues el carácter ilusorio, autocomplaciente e ideológico de esta imagen venía evidenciándose desde antes. Realidades como el crecimiento del coeficiente de Gini y el desfase entre la oferta y la demanda del mercado laboral, que condena a amplios sectores de la población a empleos precarios y mal pagados, cuando no a la sobrevivencia en la informalidad, venían siendo estudiados y denunciados desde años atrás. Pero fueron las elecciones del 2018 las que colocaron al país frente al espejo de una realidad bastante menos halagüeña que la imagen oficial.

La demografía electoral de la primera vuelta ha sido y será diversamente analizada. Una "explicación" que circuló durante la campaña y que no explica 
nada pues no analiza sino reitera el conflicto, pero cuya simplicidad, por no decir simplismo, le dio cierta popularidad, es la de una lucha grosso modo equiparable al enfrentamiento entre el bien y el mal. En el sector laico-modernizante, esta explicación tomó la forma de una lucha entre la educación y la ignorancia o, según su formulación más radical, entre la civilización y la barbarie, entre una población sometida al oscurantismo religioso y el sector educado y progresista. En el sector cristiano-conservador, tomó la forma, aquí literalmente, de una lucha entre el bien y el mal, entre los buenos cristianos y los ateos pecadores, entre los defensores de los valores y los carentes de ellos. En ambas versiones, se trata de un maniqueísmo que es mejor ignorar.

Esbozaré aquí una posible razón para la demografía electoral en la primera vuelta: el impacto de los modelos de desarrollo y procesos de modernización. De la década del 40 a la del 70, el período socialdemócrata, el país logró una progresiva disminución de la pobreza, que crece rápidamente durante la crisis a principios de los 80 ; luego decrece y, a partir de mediados de los 80 , la etapa aperturista y liberalizante, se estanca en alrededor del $20 \%$, al tiempo que empieza a incrementarse la desigualdad medida por el coeficiente de Gini o, más recientemente, el de Palma. Todo ello incidió en las conductas electorales. Durante el período socialdemócrata, mucha de la población socioeconómicamente rezagada experimentó una mejora en sus condiciones de vida o mantuvo la esperanza de lograrla, y se mantuvo fiel al bipartidismo, en especial al PLN. Cuando los procesos de reducción de pobreza se estancaron y la inequidad empezó a crecer, dichos sectores buscaron otras alternativas electorales, que lograron variables fracciones legislativas, y poco a poco mellaron al bipartidismo. El proceso desembocó en la emergencia del PAC, que, tras consolidarse como partido con representación legislativa importante, ganó la elección presidencial en el 2014. En el 2018, se produjo una nueva emergencia, de futuro incierto: el electorado evangélico. La mezcla de pobreza estancada, inequidad creciente y la pesada sombra de la corrupción minó al bipartidismo. Los sectores populares y conservadores, en especial rurales, encontraron refugio en $\mathrm{RN}$, mientras las clases medias y los sectores laicizantes, en especial urbanos, en el PAC.

La primera vuelta constituyó un referendo no solo sobre los modelos de desarrollo, sino también sobre los procesos de modernización de las últimas décadas. Los sectores populares, en especial rurales, principales perdedores 
de dichos procesos, golpeados por la creciente inequidad y atrapados en el círculo de una pobreza estancada, votaron contra la continuación del proceso apostando por una imposible restauración de la idealizada sociedad patriarcal tradicional. Las clases medias, en cambio, en especial las urbanas, así como los sectores privilegiados, se habían beneficiado de la modernización. No tanto, o al menos no solo, en términos estrictamente económicos, sino por la ampliación de los proyectos de vida permitidos. Como los sectores populares, esa clase media estaba inconforme con el desgaste y los abusos del bipartidismo, pero, a diferencia de aquellos y ante la evidencia de un bipartidismo opuesto a la modernización sociocultural, buscó alternativas que posibilitaran dicha modernización.

Lejos de ser una lucha entre la ignorancia y la educación, o entre la debacle y la regeneración moral, los distintos sectores votaron según les había ido en los incompletos procesos de modernización del país. Los perdedores expresaron su rechazo y pidieron no solo un alto en el camino, sino una vuelta atrás, y los ganadores exigieron no solo que no se detuviera, sino que avanzara, de una vez por todas, en los temas en que más estancado estaba. Para los sectores populares la elección fue, además, un masivo voto de protesta contra la clase política en su conjunto, que con al bipartidismo ahora incluía también al PAC; para los sectores modernizantes, una prueba de la fuerza con que amplias secciones de la población rechazaban profundizar la modernización. Igualmente, debería considerar las razones que sus adversarios tenían para rechazar una modernización, la cual les había traído pocos beneficios y sí una creciente exclusión.

Las consecuencias político-electorales de la primera vuelta fueron de peso. Quienes representaron más claramente las visiones en conflicto y ofrecían más posibilidades de triunfo se impusieron sobre quienes mantuvieron posiciones más acomodaticias o ambiguas en los temas definitorios de la campaña, así como sobre quienes no ofrecían posibilidades de triunfo electoral.

Los resultados fueron un nuevo golpe al bipartidismo como tal, pero, mientras el PUSC salió fortalecido, el PLN salió debilitado. Los resultados del PUSC, sin alcanzar los de antaño, representaron una nueva mejoría frente a los anteriores, un proceso favorecido por el alejamiento de Rafael Ángel Calderón Fournier y la muerte política de Miguel Ángel Rodríguez. 
Sin la sombra de los dos expresidentes que causaron su debacle, el partido se ha rearmado alrededor de la figura de Rodolfo Piza.

Para el PLN, en cambio, la primera vuelta fue un golpe cuyas consecuencias están por verse, pero algunas de cuyas causas son discernibles. El PLN agrupó y representó, de su nacimiento hasta los 70, a las clases medias emergentes y modernizadoras creadas o reforzadas por el proyecto socialdemócrata. El surgimiento de élites liberacionistas, el reiterado acceso al poder y la crisis de fines de los 70 e inicios de los 80 habían empujado al PLN a sustituir sus raíces socialdemócratas por el llamado Consenso de Washington, avalado por élites nacionales e internacionales pero rechazado por amplias capas de la población nacional y mundial. Lo anterior, unido a las crecientes denuncias de corrupción, debilitaron al partido sin quitarle su rol de principal partido político. Luego vinieron las derrotas del 2014 y el 2018, producto, entre otros factores, de candidatos que no generaban entusiasmo ni siquiera en el propio PLN y de la incapacidad de leer los cambios socioculturales del país.

La impopularidad de sus últimos dos candidatos presidenciales subraya el contraste con los resultados de las elecciones legislativas. En el 2010, Laura Chinchilla gana la presidencia y el PLN obtiene veinticuatro curules, que pasan a dieciocho en el 2014 y a diecisiete en el 2018, así que fueron, en los tres casos, la mayor fracción. Ello indica que sigue siendo el partido con una base electoral más amplia y estable, suficiente para ganar elecciones legislativas, pero no las presidenciales.

El doble proceso de una base electoral que se va erosionando y una creciente dificultad de atraer votantes fuera de esta base se relaciona con la incapacidad mostrada para sintonizar con los nuevos anhelos y enojos que mueven al electorado. Mientras las viejas lealtades partidarias van desapareciendo y surge un electorado que decide su voto de manera coyuntural, el PLN sigue apelando, cada vez más inútilmente, a la "familia liberacionista". Si su principal baluarte habían sido las clases medias que había ayudado a crear y ampliar, se ubica cada vez más a contramano de los temas que mueven a estos sectores. En un tópico como la problemática ambiental, un gobierno del PLN declara de utilidad pública una mina a cielo abierto, una de las actividades más destructivas del ambiente. En el tema de los derechos humanos, en el 2012, la fracción del PLN lleva a Justo Orozco 
a presidir la Comisión de Derechos Humanos de la Asamblea Legislativa. Si el asunto de la corrupción por poco destruye al PUSC, al PLN lo afectó bastante. De triste memoria son casos como el del entonces diputado Jorge Angulo, sobre quien se acumularon numerosas acusaciones y evidencias de corrupción desde julio del 2011 y a quien el partido no suspendió sino hasta enero del 2012, cuando la situación era insostenible y el daño estaba hecho. Crecientemente alejados de uno de sus previos bastiones electorales, los triunfos presidenciales del PLN en el 2006 y 2010 se debieron al respaldo de los sectores más vulnerables al clientelismo: la población de las zonas periféricas del país. Cuando esta no vio su apoyo convertido en mejoras en sus condiciones de vida, pero sí un aumento de las desigualdades sociales, dejó de votar por el PLN y vino la derrota del 2014, así como la debacle del 2018. La evolución de la previa propuesta socialdemócrata del crecimiento con redistribución a un modelo aperturista de crecimiento económico sin redistribución no había anulado la vocación modernizante del PLN. Pero, conforme amplios sectores de la sociedad civil se modernizaban, en especial las clases medias, sectores importantes del PLN empezaron a tejer alianzas con otros culturalmente conservadores. La cercanía de Laura Chinchilla con la Iglesia católica le mereció la declaratoria como "hija predilecta de la Virgen de los Ángeles”, y Johnny Araya, tras recobrar la alcaldía de San José con un partido evangélico, volvió al PLN. Álvarez Desanti tejió fuertes vínculos con el evangelismo, propició en el 2017 la elección del primer presidente legislativo de un partido evangélico y, cuando en el 2018 estalló el conflicto cultural que definiría la primera ronda, se situó del lado conservador y apoyó a Fabricio, a contramano de la mayoría de los votantes del PLN, quienes lo hicieron por Carlos Alvarado.

Otro gran perdedor fue el Frente Amplio (FA), que solo obtuvo un diputado. Tras obtener nueve en las elecciones del 2014, el FA parecía encaminado a consolidar una alternativa de izquierda, la cual nunca había tenido tantas diputaciones ni recibido tanto apoyo en la elección presidencial. La creciente inequidad del país parecía haber creado un ambiente favorable a la izquierda, pero la decisión de José María Villalta de no aspirar de nuevo a la presidencia privó al FA de su político más popular y el conflicto sociocultural afectó sus posibles apoyos electorales. Con el voto girando alrededor del conflicto entre conservadurismo y modernización, el FA apoyó decididamente 
la modernización, mientras el voto popular apoyaba al conservadurismo. En cuanto a los sectores de clase media que lo habían apoyado en el 2014, asustados por la posibilidad real de triunfo de Fabricio Alvarado, optaron por el voto útil y se congregaron alrededor de Carlos Alvarado.

El tercer gran perdedor fue el ML, que tras obtener nueve diputaciones en el 2010 había pasado a cuatro en el 2014 y en el 2018 no logró ninguna. Endeudado y en virtual bancarrota, acechado por las acusaciones de corrupción contra su líder Otto Guevara y dividido por su empecinamiento en ser de nuevo su candidato presidencial, es probable que este haya sido el fin del partido como tal, pero es factible que intente resucitar con otro nombre. También se hundieron los partidos Renovación Costarricense, Alianza Demócrata Cristiana y Accesibilidad sin Exclusión, que juntos tenían cuatro diputaciones y, tras defender posiciones similares a las de $\mathrm{RN}$, fueron víctimas del triunfo de este y quedaron sin representación legislativa.

El gran triunfador de la primera vuelta fue $\mathrm{RN}$, que pasó de un diputado en el 2014 a catorce en el 2018, un crecimiento tan inesperado que tomó por sorpresa al propio partido. Más que de RN como tal, el triunfo fue de los sectores conservadores cristianos, en especial evangélicos, muy fuertes en segmentos desfavorecidos de la población, y con sus bastiones concentrados en las áreas periféricas del país. Es posible que una parte del voto popular de protesta que antes había apoyado al FA haya sido captada por RN, pero harían falta estudios empíricos para comprobar o descartar esta posibilidad.

Ganadores menores fueron dos partidos pequeños: el PIN, que tras varias elecciones sin conseguir diputaciones logró cuatro, gracias al impulso que le dio su polémico candidato presidencial Juan Diego Castro, y el Republicano Nacional, agrupado alrededor de la figura de Rafael Ángel Calderón Fournier, que en su primera campaña logró sacar dos legisladores.

En cuanto al PAC, sus resultados electorales en la primera vuelta son contradictorios. El éxito de su candidato presidencial, al ubicarse en segundo lugar, superando a los candidatos del bipartidismo, y el haber conseguido pasar a la segunda vuelta por segunda vez consecutiva, pese al desgaste del primer gobierno del PAC y a los virulentos ataques mediáticos y de otros candidatos durante la campaña, lo colocan en el bando de los ganadores. Pero la paulatina disminución en el número de diputaciones obtenidas respecto a elecciones anteriores (diez en el 2018 frente a once en el 2010 y trece en 
el 2014), así como su debilidad en las zonas costeras hacen ver que el éxito de su candidato presidencial es solo la mitad de la historia y que el afianzamiento del partido, en el nivel nacional es, en el mejor de los casos, parcial.

\section{Segundo clivaje político-electoral}

La necesidad de una segunda ronda electoral presidencial ocho semanas después de la primera, reducida a los candidatos del PAC y RN, obligó a los otros partidos y a sus votantes a tomar decisiones, lo cual generó una recomposición del panorama y los discursos electorales.

La primera vuelta había tenido dos bandos nítidamente opuestos: el laico-modernizante y el conservador-cristiano, más diversas opciones en el medio. Ello cambió en la segunda vuelta; una de las razones fueron los cambios referentes al rol y a la presencia de la religión. Si antes Fabricio y RN habían apelado sistemáticamente a argumentos y valores de tipo religioso, ahora, buscando ampliar su atractivo electoral y tal vez aconsejados por nuevos asesores, intentaron atenuar este tipo de discurso. Redoblando los ataques al gobierno del PAC, Fabricio se acercó a círculos empresariales, grupos de pensamiento económico conservador y a los sectores más conservadores del PLN y el PUSC. Ello fue facilitado por la notoria falta de cuadros profesionales de $\mathrm{RN}$, un partido que, al iniciar la campaña, ni soñaba con el triunfo obtenido y menos aún se había preparado para este. Diversos sectores conservadores soslayaron las posiciones que no compartían en temas de derechos humanos, los cuales no consideraron relevantes, a cambio del ofrecimiento de que en un gobierno de RN ellos definirían y manejarían las políticas económicas. Al tiempo que Fabricio suavizaba su discurso religioso y matizaba posiciones previas como salirse de la $\mathrm{CIDH}$, sus nuevos aliados enfatizaron que lo importante era la agenda económica, vendiendo la idea de un eventual gobierno más moderado en temas socioculturales y tecnocrático en política económica.

También Carlos Alvarado se vio obligado a sumar apoyos electorales. Para ello, soslayó su afiliación partidaria, se presentó como un candidato nacional ("Es por Costa Rica"), así como concretó alianzas con diversos sectores y actores, destacando la firmada con Rodolfo Piza, al igual que el apoyo de figuras del PLN como Leonardo Garnier y María Luisa Ávila. El 
apoyo del movimiento no-partidario Coalición por Costa Rica fue decisivo, pues validó el proclamado carácter nacional del candidato y movilizó en su favor tanto el voto como el proselitismo de gran cantidad de jóvenes. En resumen, logró atraer por igual a sectores más conservadores y más liberales que el candidato. Pero uno de los principales reacomodos lo provocó el círculo íntimo de Fabricio: la sombra de Ronny Chaves, pastor personal de Fabricio, creció en la campaña, cuando los estrambóticos ataques de Chaves contra el catolicismo, en particular contra la Virgen de los Ángeles, generaron una fuerte reacción de amplios sectores católicos.

La campaña tomó nuevos rumbos. Antes de la primera vuelta, el bando proreligioso abanderado por Fabricio carecía por completo de facetas tecnocráticas e incluía por igual a evangélicos y católicos. Por su parte, Carlos había abanderado posiciones laicas y destacaba por su formación y manejo de información. Ahora, rumbo a la segunda, Fabricio intentó adquirir una cara menos cristiana y más tecnocrática, mientras Carlos, sin haberlo buscado, atrajo a sectores católicos que resentían los ataques a la Negrita (Vírgen de los Ángles, reconocida como patrona de Costa Rica).

Simplificando mucho, un posible resumen del proceso electoral sería el siguiente: una primera etapa, que va hasta principios de enero del 2018, en la que intentan plantearse temas como el empleo, pero acaba dominando el de la corrupción; una segunda, de principios de enero hasta la primera vuelta, cuando la campaña se reacomoda alrededor de dos visiones antagónicas en temas de derechos humanos y rol de la religión, y una tercera etapa, entre la primera y la segunda vuelta, en la que el previo antagonismo de sus dos candidatos se difumina algo por el anuncio de políticas económicas afines, el menor rol de la religión en la campaña de Fabricio y el apoyo de sectores católicos a Carlos, respaldo que diluyó el previo antagonismo entre los bandos sobre el rol de la religión en la vida social. Que este desdibujamiento no eliminara la polarización entre la visión laica y modernizante y la anclada en el conservadurismo cristiano demuestra que tanto los temas de derechos humanos como el de la modernización en general conservaron toda su relevancia y siguieron alimentando las pasiones.

Ambos candidatos recibieron los votos de quienes apoyaban sus propuestas y los de quienes no lo hacían, pero cuyo rechazo a las del otro los hizo respaldar a alguien por quien en otras circunstancias no hubieran 
votado. Más que en otras elecciones presidenciales, la del 2018 fue decidida no solo, y tal vez no tanto, por el apoyo al ganador, sino por el rechazo al perdedor. En la primera vuelta, Fabricio se alimentó del rechazo cristiano a las acciones de la CIDH y, en la segunda, sumó el rechazo de diversos sectores al PAC. Carlos, por su parte, en la primera vuelta se alimentó del rechazo laico a las posiciones religiosas de Fabricio y, en la segunda, sumó el rechazo católico a los ataques de Ronny Chaves a la Negrita, con lo que el enfrentamiento inicial entre laicos y religiosos adquirió tintes de conflicto entre evangélicos y católicos. El proceso mantuvo su carácter de referendo entre una visión cristiano-conservadora y otra laica-modernizante, pero el triunfo de esta última se vio diluido por el hecho de lograrlo con el apoyo de amplios sectores católicos.

\section{Panorama actual y perspectivas a corto plazo}

El actual panorama del país lo caracterizan la incertidumbre, la volatilidad y la conflictividad. Parece haber algunos consensos en el ámbito económico, pues la reducción del déficit fiscal, el ordenamiento del gasto público, así como el combate a la evasión y la elusión fiscales son metas aceptadas por muy amplios sectores. Pero también aquí tomar medidas de fondo resulta difícil. Los sectores con más capacidad de presión difieren sobre la naturaleza y solución de los problemas. Los sindicatos públicos, únicos de peso, se oponen a medidas que toquen las dispares estructuras salariales de sus gremios y reclaman, con justicia, que se combata la evasión y la elusión fiscal. Las cámaras empresariales usan su enorme capacidad de torpedear medidas que los hagan tributar como corresponde e insisten en la reducción y ordenamiento del gasto público, especialmente en recortar los beneficios laborales del empleo público. El Gobierno, que en principio tiene la iniciativa y debe actuar como árbitro, tiene las manos bastante amarradas. Los automatismos y disparadores presupuestarios le impiden tomar medidas fiscales de fondo, que son potestad de una Asamblea Legislativa voluble y fragmentada, marcada por el tamaño y características de la fracción de RN, lo reducido de la fracción oficialista y los intereses del bipartidismo, al igual que de los sectores que representa, todo lo cual dificulta cualquier concertación interna o con el Gobierno. 
Paralelas a las presiones sindicales, empresariales y partidarias, se oyen otras voces y un silencio. Las voces, técnicas, aunque no por ello neutrales, provienen de distintos organismos internacionales y sectores académicos que advierten, cifras en mano, los riesgos de no tomar medidas. El silencio, ominoso y preocupante, es el de los sectores más desprotegidos de la población, carentes de organismos que los representen y presionen por sus intereses. Está la enorme cantidad de empleados del sector privado con salarios muy bajos y condiciones laborales precarias que, por ejemplo, imposibilitan organizar sindicatos. También está el alto porcentaje de la población que trabaja de manera precaria en el sector informal, sin derechos laborales ni ingresos adecuados o estables. Se critica mucho, con justicia y sin ella, las condiciones laborales y salariales del sector público. También se habla, aunque casi nada en los principales medios de comunicación, aliados del sector privado, de los abusos empresariales mediante la evasión y la elusión fiscales. Pero pocos parecen interesarse en, y menos en representar a, esa mayoría de la población que tiene empleos mal pagados y condiciones laborales adversas o que carecen de ingreso fijo y derechos laborales. Esta población no es defendida por los sindicatos públicos y menos aún por las cámaras del sector privado, pero, como ya ha sucedido, será la más afectada si se desata una crisis fiscal. Es previsible, entonces, que las posibles reformas fiscales no presten la atención debida a los estratos más vulnerables, algunos de ellos atendidos por las políticas sociales, pero casi todos excluidos de las económicas. De ser así, la inequidad y la conflictividad seguirán creciendo, con todo lo que ello implica para la coexistencia social y los proyectos de país.

En el nivel político-partidario el panorama no es menos incierto. Es imposible predecir el futuro a mediano plazo de Restauración Nacional, el gran ganador de las elecciones. El aumento de la población evangélica y de la movilización política de ella, más la red de templos evangélicos, cuya actividad mezcla fácilmente lo religioso y lo político, son factores que apuntan a su posible consolidación. Pero la gran volubilidad del electorado; las disensiones y limitaciones de su fracción legislativa; las luchas de poder entre el líder tradicional de RN, Carlos Avedaño, y el equipo de Fabricio Alvarado; las acusaciones contra el partido; el carácter polimorfo y atomizado del evangelismo, todavía minoritario en el país, y las reacciones generadas 
tanto por algunas posiciones del partido como por sus allegados introducen mucha incertidumbre en el futuro electoral del partido.

En el PLN, la situación es de crisis. Obtener la mayor fracción legislativa compensó algo la debacle presidencial, pero su base electoral se va erosionando, las dos últimas elecciones no tuvieron candidatos presidenciales ni propuestas que atrajeran otros votantes y evidencian una fuerte indefinición ideológica. Tras décadas de tendencia socialdemócrata, seguidas de otras más aperturistas y menos redistributivas, pero siempre modernizantes, en la segunda vuelta el discurso altamente conservador y el apoyo a Fabricio de buena parte de la dirigencia, Álvarez Desanti incluido, aumentó la desconexión entre la dirigencia y base liberacionista que votó mayoritariamente por Carlos Alvarado. Hubo también pesados silencios; el más significativo fue el de Óscar Arias, posible indicio de su creciente retiro de la política activa, de un ocaso de su liderazgo partidario o de una mezcla de ambas. Recordemos que Laura Chinchilla, candidata del arismo, rápidamente se distanció de Arias; Johnny Araya derrotó al arismo en el 2013, y, aunque Álvarez Desanti fue apoyado por el arismo, sus relaciones con Óscar Arias no fueron las mejores. Con este último sin la voluntad o el liderazgo que le permitió recomponer al PLN tras las derrotas electorales del 2002 y el 2006 y por el momento sin otro líder capaz de aglutinar al partido, se dará el posible enfrentamiento entre el sector que desea retomar posiciones socialdemócratas y culturalmente modernizadoras y los sectores más conservadores. El PLN no está condenado a seguir perdiendo peso político, pero no goza de buena salud ni su recuperación está garantizada.

Significativa es la crisis del FA, por ser la única fuerza de izquierda con representación parlamentaria desde el 2002. Además de la debacle de pasar de nueve diputados en el 2014 a solo uno en el 2018, el FA parece atrapado en los conflictos culturales que sacudieron el panorama político nacional. Partido de izquierda democrática, el FA ha defendido intereses socioeconómicos de sectores populares y marginales de la población, pero el voto se definió por temas socioculturales, no socioeconómicos. Al defender la visión laica y modernizante, el FA se distanció del grueso de los sectores populares, sin lograr a cambio el apoyo de unas clases medias que, por no ser de izquierda o por apelar al voto útil, prefirieron a Carlos Alvarado. En esa medida, buena parte del futuro del FA, y de la izquierda en general, 
tal vez dependa de si logra mayor apoyo de los sectores que defienden la visión laica y modernizante, o si alcanza reconectar culturalmente con los sectores populares.

En cuanto al PUSC, su dirigencia se dividió en la segunda vuelta entre quienes apoyaron al candidato del PAC y quienes optaron por el de $\mathrm{RN}$, pero la alianza de Rodolfo Piza con Carlos Alvarado hizo que la escisión fuera menor, o menos visible, que en el PLN. Hubo otra diferencia significativa: mientras el grueso de la dirigencia del PLN apoyó posiciones más conservadoras que las de su base, la del PUSC respaldó, igual que su base, posiciones más liberales que las tradicionales del partido. Este giro, dados los cambios culturales y demográficos del electorado nacional, debería favorecerlo a futuro. Respecto a la prominencia de Rodolfo Piza en el actual gobierno, es prematuro especular sobre sus posibles efectos en el PUSC.

En lo tocante al futuro de partidos pequeños como el Republicano y el Independiente, en nuestro país el ciclo de vida de este tipo de agrupaciones ha sido corto: alcanzan representación legislativa en una o más elecciones y luego desaparecen, en especial si dependen de una figura política visible y carecen de una línea política coherente. Tales fueron los casos del Partido Unión Agrícola Cartaginesa, creado alrededor de la figura Juan Guillermo Brenes Castillo, "Cachimbal"; del Partido Nacional Independiente, creado por Jorge González Martén, y del PASE, nucleado alrededor de Óscar López. En el caso del PIN, su futuro parece precario, pues Juan Diego Castro, tras relanzarlo, se alejó y se llevó a uno de los cuatro diputados obtenidos. En cuanto al Republicano Independiente, la prominencia que en él tienen las figuras de Calderón Fournier y el Dr. Rodolfo Hernández tal vez le permitan una vida algo más longeva, pero difícilmente le instarán seguir creciendo.

Quebrar más de medio siglo de partidismo y ganar dos elecciones presidenciales seguidas parece probar la consolidación del PAC, pero la realidad es más compleja. Pese a sus logros, la imagen del gobierno de Luis Guillermo Solís acabó deteriorada por sus errores, el desgaste de todo gobierno, y el virulento ataque mediático y político alrededor del "cementazo". Conforme avanzaba la campaña, Carlos Alvarado fue tomando distancia frente al Gobierno y el partido, lo que se acentuó tras la primera vuelta, cuando su condición de candidato del PAC fue sepultada bajo el llamado a votar "por Costa Rica" y por un gobierno tanto nacional como pluripartidario, por lo 
que su triunfo es solo parcialmente transferible al PAC, idea reforzada por los débiles resultados partidarios en las elecciones legislativas. El hecho, con todo, es que la hecatombe anunciada por algunos, tras su primer triunfo presidencial, no se produjo, y, pese a las críticas, el PAC superó con relativo éxito la prueba de fuego. Expirando su primer gobierno y en unas elecciones que polarizaron al país como no sucedía hacía mucho tiempo, el candidato del PAC superó al bipartidismo y en la segunda vuelta obtuvo el $60 \%$ de los votos. En momentos en que buena parte del electorado consideró que estaba en juego no solo el próximo gobierno, sino su futuro a corto y mediano plazo, su candidato obtuvo un amplio respaldo. El PAC parece haber consolidado una base electoral menos extensa, estridente y monolítica que las del bipartidismo; además, amplios sectores del electorado parecen no considerar al PAC como una opción muy atractiva, pero sí mejor que las otras.

El PAC puede seguir siendo lo que ha sido: un partido de centro que abarca sectores liberales y conservadores por igual, una mezcla que fue más fácil de sostener cuando los conflictos entre estos bandos no habían estallado. Ya habiendo estallado, habrá que ver si el PAC define una línea más clara en temas como los que marcaron la campaña.

Todo lo dicho permite afirmar el panorama nacional actual y, a corto plazo, está marcado por la volatilidad, la incertidumbre y una conflictividad sociocultural asociada a diferencias político-económicas. La volatilidad y la incertidumbre están presentes en todo nivel. Entre los muchos factores internacionales que alimentan este clima, podemos citar los conflictos comerciales desencadenados por la administración Trump, los precios del petróleo, los populismos europeos de derecha y la crisis en Nicaragua. En el nivel nacional, operan, por ejemplo, la incertidumbre sobre la reforma fiscal, la crisis del Poder Judicial, la del bipartidismo, la derrota de la izquierda, el carácter multipartidario y pluri ideológico del Gobierno, las incógnitas sobre la fracción de RN y un PLN sumergido en la confusión interna, sin una línea sociopolítica clara ni figuras capaces de unificarlo.

El actual gobierno surgió de alianzas con sectores dispares y del voto de segmentos distintos e incluso antagónicos, una pluralidad presente en el gabinete ministerial y otros altos cargos, lo cual también puede generar incertidumbre sobre sus principales líneas de acción en diversos ámbitos. 
En el campo económico, el acuerdo con Rodolfo Piza, el déficit fiscal, la derrota de la izquierda y algún grado de consenso nacional vuelven previsible una política de austeridad fiscal, mediante el doble intento de aumentar la recaudación y tanto controlar como ordenar el gasto público; el desacuerdo está en cómo hacerlo. La mejora fiscal puede lograrse priorizando la reducción del gasto público y haciendo que la factura la paguen las clases medias y populares o aumentando la recaudación con una reforma que consiga que los sectores más beneficiados tributen más y no solo que evadan, sino que eludan menos, alternativas que marcarán buena parte de la deriva económica y social del país los próximos años. Aceptada la necesidad de ordenar, redireccionar y hacer más eficiente buena parte del gasto público, lo cierto es que, si no se logra un aumento en la recaudación con una estructura tributaria más justa y menos regresiva, es muy posible un incremento en la conflictividad social alrededor de los problemas socioeconómicos que operaron de trasfondo a los de tipo sociocultural.

Si en el ámbito económico lograr consenso será difícil, mucho más lo será, por no decir imposible, alcanzarlo en los temas de conflicto cultural. Algunos, como el matrimonio civil igualitario y los derechos de las personas trans a definir su identidad de género, han empezado a avanzar y podrían seguirlo haciendo, gracias a decisiones judiciales internacionales y locales. Otras problemáticas, en cambio, como el estado laico, la reglamentación de la ley vigente sobre el aborto y en general el rol de la religión tanto en la legislación como en la convivencia social, prometen generar muchos conflictos no solo en la Asamblea Legislativa, sino en una población dividida en tres grandes bloques: el laico-modernizante, que espera cambios significativos en estos temas y demandará al presidente coherencia con su discurso de campaña en estos temas; el cristiano-conservador, con amplia representación legislativa, que intentará torpedear cualquier intento en este sentido, boicoteando proyectos en ámbitos como el económico, de ser necesario, y un tercer sector, muy polimorfo, compuesto de personas que apoyan o adversan en diverso grado estas agendas, pero no las consideran tema prioritario. Por su posible carácter mayoritario, este sector podría tener un gran peso en la discusión y en las decisiones que al respecto se tomen en el Gobierno, en la Asamblea Legislativa y al interior de los partidos en proceso de recomposición interna. 
El país enfrenta, entonces, un panorama de incertidumbre y volatilidad en una situación de conflicto sociocultural que dificulta tomar decisiones de peso, incluso en los pocos temas en los que se vislumbra algún consenso. Mientras tanto, la economía del país, que combina sectores dinámicos y otros bastante rezagados como los campesinos empobrecidos, podría enrumbarse hacia situaciones difíciles. Sin una fiscalidad más progresiva, persistirá el aumento en la inequidad y, sin un aumento en la recaudación y un reordenamiento del gasto público, es previsible una fuerte crisis fiscal. Cualquiera de estas situaciones por sí sola, o ambas combinadas, acarrearía más conflictividad social y mayor rezago de los sectores menos favorecidos.

Soy cautamente optimista. El Gobierno ha venido tomando medidas difíciles utilizando, antes que se disipe, el capital político de su amplio triunfo y su carácter multipartidario debiera incrementar su representatividad, así como facilitar algo sus relaciones con la Asamblea Legislativa, al igual que con diversas fuerzas políticas y sociales. Pero lo cierto es que vivimos tiempos de incertidumbre, convulsiones, cambios y conflictos. Aun si las de nuestro país se fueran resolviendo de forma aceptable, diversas situaciones en Centroamérica, América Latina y el mundo en su conjunto hacen prever que se avecinan momentos turbulentos.

\section{Referencias bibliográficas}

Estado de la Educación. Programa Estado de la Nación. Recuperado de estadonacion.or.cr Estado de la Nación. Programa Estado de la Nación. Recuperado de estadonacion.or.cr Estado de la Región. Programa Estado de la Nación. Recuperado de estadonacion.or.cr Jiménez Matarrita, A. (2002). El imposible país de los filósofos. San José: Editorial Universidad de Costa Rica.

Molina Jiménez, I. (2016). La educación en Costa Rica de la época colonial al presente. San José: EDUPUC.

Molina Jiménez, I. y Lehoucq, F. (1999). Urnas de lo inesperado. Fraude electoral y lucha política en Costa Rica (1901-1948). San José: Editorial Universidad de Costa Rica.

Oconitrillo García, E. (1980). Los Tinoco (1917-1919). San José: Editorial Costa Rica.

Pérez Brignoli, H. (2018). Historia global de América latina. Del siglo XXI a la independencia. Madrid: Alianza Editorial.

Putnam, L. (2013). Elisabet Saborío (trad). Género, poder y migración en el Caribe costarricense 1870 -1960. San José: INAMU.

Rodríguez, E. (editor). 1979. El pensamiento liberal. Antología. San José: Editorial Costa Rica. 
Solís, M. A. (2011). La violencia política de los años cuarenta y su lugar en el imaginario nacional. Anuario de Estudios Centroamericanos, 37, 189-200.

Viales Hurtado, R. (editor). 2013. La conformación histórica de la región Atlántico/Caribe costarricense: (Re)interpretaciones sobre su trayectoria entre el siglo XVI y el siglo XXI. San José: Editorial Nuevas perspectivas.

Viales Hurtado, R. (1998). Después del enclave 1927-1950. Un estudio de la Región Atlántica costarricense. San José: Editorial Universidad de Costa Rica. 